FILOLOGÍA FRANCESA 



\title{
MITRIDATISMO EN EL RENACIMIENTO FRANCÉS: EL PANTAGRUEL DE RABELAIS
}

\author{
Alicia Yllera \\ UNED \\ ayllera@flog.uned.es
}

\section{RESUMEN:}

Estudio del plurilingüismo en el Pantagruel de Rabelais, tras analizar la noción actual de «plurilingüismo», particularmente importante en la literatura francófona, así como diversos ejemplos de plurilingüismo en la literatura griega y latina, y en la literatura francesa medieval. Se establecen una serie de hipótesis acerca del plurilingüismo en esta primera obra de las historias de gigantes de Rabelais, que encierra los dos episodios más célebres de plurilingüismo del autor.

Palabras Clave: mitridatismo; plurilingüismo; Renacimiento francés; Pantagruel de Rabelais.

RESUMÉ:

Cet article analyse le plurilinguisme dans le Pantagruel de Rabelais, après avoir pris en compte ce que le plurilinguisme littéraire signifie de nos jours, surtout dans la littérature francophone. On souligne également les exemples de plurilinguisme qui ont précédé Rabelais dans la littérature grecque et latine, et dans la littérature du Moyen Âge français. On établie aussi un certain nombre d'hypothèses à propos du plurilinguisme dans cette première œuvre des récits de géants de Rabelais, œuvre qui contient les deux épisodes les plus célèbres de plurilinguisme de l'auteur.

Mots CLEFs: mithridatisme; plurilinguisme; Renaissance française; Pantagruel de Rabelais. 


\section{UN VIEJO FENÓMENO «REVISITADO»}

Una antigua leyenda sumeria, narrada en textos literarios probablemente compuestos durante la tercera dinastía de Ur (2550-2340 a. C.) y conservada en tabletas cuneiformes, habla de una época dorada en la que el hombre, libre de animales dañinos y de temores, vivía en un mundo de paz y prosperidad, en el que todos hablaban una misma lengua y adoraban al mismo dios, Enlil. Pero Enki, el dios sumerio de la sabiduría, confundió su habla. No se explican las razones de este hecho, aunque pudo deberse a celos de Enki hacia Enlil por el dominio universal sobre la humanidad que mostraba (Kramer, 1968). La leyenda sumeria es un precedente del relato del Génesis $(11,1-9)$ sobre la confusión de las lenguas, relato que ejercería una gran fascinación a lo largo de la historia del mundo occidental.

Hablar hoy de «plurilingüismo» ${ }^{1}$, referido a la literatura francesa, parece que es hablar de lo que se ha dado en llamar «francofonía». Es cierto que la reflexión sobre las lenguas en contacto dentro de una misma obra literaria ha cobrado gran importancia en los estudios sobre literatura francófona (en especial canadiense), sobre todo a raíz de los diversos trabajos de Lise Gauvin. Hay que reconocer que son numerosos los ejemplos de plurilingüismo en diversos autores francófonos ${ }^{2}$. El plurilingüismo conoce cierto éxito en la literatura contemporánea, como también el mito de Babel que intenta explicar la diversidad de lenguas que dificultan la comunicación entre pueblos distintos. Se ha observado que el término «Babel» es cada vez más frecuente en títulos de novelas, poemas, álbumes musicales francófonos, etc. (cf. Khordoc, 1999: 130-131). Pero también el plurilingüismo fue sentido como característico de las vanguardias de los años 1910, 1920 y 1930, cuando las revistas vanguardistas eran una verdadera Babel de lenguas y un punto de encuentro internacional (Bruera y Meassi, 2011), y tuvo una importante función cómica en el teatro francés de la Belle Époque, pues el francés deformado de los extranjeros llegados a la capital (especialmente hispanoamericanos, eslavos y anglosajones) divertía al público parisiense (Coste, 2001).

A pesar del interés del plurilingüismo en la literatura contemporánea francesa y francófona, no puede olvidarse la importante tradición que, con grandes precedentes clásicos, arranca de los primeros textos romances y cuenta con momentos de gran esplendor durante la Edad Media y especialmente en el siglo XVI. Decae a fines del siglo XVII, aunque sin desaparecer nunca totalmente, y cobra nueva vida a partir del Romanticismo.

\footnotetext{
${ }^{1}$ Entenderemos «plurilingüismo» en sentido estricto, como presencia de varias lenguas o dialectos en un mismo texto o enunciado, y no en el sentido amplio en el que empleó el término Bajtín (1989: 117-148), como equivalente a «polifonía». En el concepto bajtiniano se incluyen no solo la presencia de lenguas o dialectos distintos de la lengua de base y de diversos registros sociales o niveles de lengua, sino también la diversidad de voces individuales que pueden aparecer, por ejemplo, en una novela. Esto supone multiplicar los ejemplos de plurilingüismo hasta el infinito, haciendo inoperante el concepto mismo. En el Renacimiento se habla de «mitridatismo», en recuerdo de Mitridates VI Eupator, rey del Ponto, capaz de hablar las veintidós lenguas de las veintidós naciones sobre las que reinaba, en decir de Plinio el Viejo (vii, 24. 2003: 45-46 y xxv, 3. 1980: 141) y de Aulo Gelio (xvii, 17. 1978: 263).

${ }_{2}^{2}$ Habría que evitar errores flagrantes como el de Anne Marie Schöne que consideraba el fenómeno del plurilingüismo como una innovación sin precedente de la literatura inglesa del siglo XIX. Es cierto que el ejemplo de Joyce llevó a algún crítico a considerar la presencia de lenguas extranjeras en un texto como un fenómeno típicamente anglosajón (Souriau, 1965: 43).
} 
Según las épocas, géneros, autores y obras, el plurilingüismo puede tener una u otra función (lúdica, estética, realista, de reivindicación política, etc.).

El siglo XVI es, en la literatura francesa ${ }^{3}$, un momento particularmente interesante en el empleo del plurilingüismo ${ }^{4}$.

\section{Desde los albores de la literatura romance}

La introducción de párrafos (o voces) en lenguas distintas de la lengua de base en la que se redacta un texto es un procedimiento universal, que aparece desde los más antiguos textos conservados. En el mundo griego es frecuente en el teatro cómico con la presencia de extranjeros que hablan lenguas incomprensibles, un griego defectuoso o pronuncian palabras o frases en su lengua, así como también con los personajes que proceden de regiones que cuentan con un dialecto diferente del ático. Platón el Cómico puso en escena a la madre de Cleofón, que hablaba tracio. El procedimiento es particularmente importante en Aristófanes. En Los acarnienses, un ciudadano de Megara, que ha disfrazado a sus hijas contando venderlas como cerditos, habla megarense (vv. 729-835. 1972, I: 42-48), mientras que un mercader de Tebas habla beocio (vv. 860-954. 1972, I: 50-54). En Lisístrata, tres espartanos se expresan en su dialecto lacedemonio (vv. 81-253, 980-1013, 1076-1199 y 1242-1272. 1967, III: 122-130, 163-164, 167-172, 174-175). En algún breve ejemplo, el habla puede no responder al origen regional del personaje, sino que este reproduce el habla de otro, como el dialecto jónico en La paz (vv. 45-48. 1969, II: 101); etc. En otros casos se trata de un griego muy deformado en boca de un extranjero o de una jerga incomprensible. En Las tesmoforiantes, un arquero escita se expresa en una lengua medio escita medio ática (vv. 1001-1225. 1967, IV: 6071); en Las aves, un dios bárbaro habla en un lenguaje incomprensible y en un griego muy deformado (vv. 1615-1616, 1628-1629 y 1678-1681. 1967, III: 101-102, 102, 104105). En Los acarnienses, el embajador persa se expresa en un lenguaje seudopersa y seudogriego (vv. 100-107. 1972, I: 16). Una lengua de fantasía se presenta también como una lengua auténtica en el pretendido oráculo en escita de Alejandro o el falso profeta ( $\S$ 53) de Luciano (1988: 422), etc.

Por influencia griega reaparece en la comedia romana. Sobre todo, en Ponulus (El cartaginesito) de Plauto, el cartaginés Hanón se expresa en su idioma, lo que es inmediatamente traducido al latín (V, 1, vv. 930-939, 940-949 y 950-960. 2003: 225-227). Pero la comicidad de la escena siguiente reside en la pretensión del fanfarrón esclavo Milfión de conocer el púnico, cuando apenas si entiende el saludo y el nombre de los dos interlocutores, inventando el resto a partir de vagas semejanzas con voces latinas $(\mathrm{V}$,

\footnotetext{
${ }^{3}$ Por supuesto, no solo en la literatura francesa.

${ }^{4}$ No se incluirán los autores políglotas que escriben en diversas lenguas, como Du Bellay, que escribe versos en francés y versos en latín. Se atenderá exclusivamente a los textos más o menos políglotas de la época y especialmente al Pantagruel de Rabelais, autor del que se declaran herederos muchos escritores francófonos (Gauvin, 2004: 297-302). En los dos apartados siguientes me limitaré a apuntar ciertos aspectos del plurilingüismo durante la Edad Media y en el siglo XVI, sin ninguna pretensión de abarcar mínimamente un tema muy amplio y que requiere un estudio mucho más detenido del que cabe en estas páginas.
} 
2, vv. 994-1028. 2003: 229-2315). Después de la comedia arcaica, el género en el que el plurilingüismo está más presente en la literatura romana es la sátira. Las obras cómicas y satíricas serán también los géneros preferidos para introducir párrafos en lenguas extranjeras en la literatura francesa del siglo XVI. Al mismo tiempo, el ejemplo de Plauto será imitado por diversos autores de comedias eruditas del Renacimiento italiano, como el Ariosto, en la Cassaria, y Bibbiena, en la Calandria (Cortelazzo, 1980: 184-187).

Limitándonos a lo que fue el mundo galorromano, el más antiguo ejemplo de plurilingüismo es la llamada alba de Fleury, de la segunda mitad del siglo $\mathrm{X}^{6}$. En cada estrofa, los tres primeros versos están redactados en latín, los dos últimos en una lengua romance cuya identidad se discute: ¿occitano, retorrománico, bajo latín con elementos occitanos? (Zumthor, 1985: 187-290; Heller-Roazen, 200: 84-87)7.

Son célebres los poemas plurilingües del trovador Raimbaut de Vaqueiras. En Domna, tant vos ai preiada (h. 1190), un trovador provenzal y una dama genovesa alternan sus estrofas, expresándose cada uno en su lengua, dejando patente su incapacidad para entenderse. El descort Eras quan vey verdeyar (entre 1197 y 1201), del mismo autor, es más ambicioso: consta de cinco coblas, cada una en una lengua diferente (occitano, italiano, francés, gascón y tal vez galaicoportugués ${ }^{8}$ ), seguidas de una tornada con dos versos en cada lengua ${ }^{9}$. La pluralidad de lenguas produce una confusión lingüística que es un reflejo de la confusión del poeta, abandonado por su dama.

El plurilingüismo es particularmente frecuente en el teatro y en la poesía lírica, pero aparece igualmente en la novela. El plurilingüismo en la literatura francesa aumenta bastante lentamente hasta finales del XII, más rápidamente en el XIII y constituye en los siglos XIV y XV una literatura bastante abundante (Zumthor, 1960: 307-308).

El plurilingüismo aparece tanto en el teatro religioso como en el teatro profano. Alternan latín y occitano en el Sponsus o Mystère des vierges sages et des vierges folles (s. XI). El Mystère d'Adam (mitad del siglo XII) está escrito en francés, pero inserta textos litúrgicos en latín cantados por el coro, además de numerosas rúbricas escritas en esta lengua, que orientan acerca de su representación.

Las lenguas imaginarias, supuestamente habladas en países existentes, aparecen ya en el Officium Stellae, drama de Navidad de Rouen, del siglo XII. En un texto escrito en latín, uno de los tres Reyes Magos se dirige a Herodes en dicha lengua, pero los dos restantes hablan en una jeringonza incomprensible que supuestamente corresponde al habla de sus países. El dios pagano Tervagán, en el Jeu de saint Nicolas de Jean Bodel (vv. 1512-1521. 1981: 236), pronuncia unos versos ininteligibles que el rey pagano traduce al buen devoto de san Nicolás. Es también supuestamente una lengua diabólica la que pro-

5 Acerca del plurilingüismo en la literatura griega y en la latina: Coulter, 1934; Cortelazzo, 1980; Lüdi, 1995; Colvin, 1999; Willi, 2003; Oniga, 2007; Rochette, 2007; etc.

${ }^{6}$ Su nombre se debe a que el texto procede de la abadía benedictina de Fleury (hoy Saint-Benoît-sur-Loire).

${ }^{7}$ Unas décadas posterior es la más antigua jarcha que se ha logrado fechar con seguridad (1042). Muestra la persistencia del plurilingüismo en los orígenes de la literatura romance.

${ }^{8}$ Suele considerarse que la quinta estrofa está escrita en galaicoportugués, pero Menéndez Pidal (1991: 191-192) la suponía redactada en aragonés. Cf. Zink, 1995; Tavani, 2000: 129-138; Hellen-Roazen, 2003: 88; etc. Existen otros ejemplos de poemas plurilingües provenzales como los de Bonifacio Calvo y de Cerveri de Girona (Tavani, 2000: 138-142).

${ }^{9}$ Edición de ambos textos en Riquer (1975, II: 816-819 y 840-842). El minnesinger austriaco Oswald von Wolkenstein (1367-1445) compuso un poema en el que introdujo seis lenguas (Forster, 2009: 17). 
nuncia el pagano Salatino para obligar al diablo en el Miracle de Théophile (vv. 160-168. 1989-1990, II: 32) de Rutebeuf (mitad del siglo XIII). En los mystères dramáticos existen diversos ejemplos de jergas en lenguas extranjeras más o menos auténticas, así como de acumulación de lenguas diversas, como en el Mystère de la Résurrection (hebreo, griego, latín, neerlandés, bretón) o en el Mystère des Actes des Apôtres (Cohen, 1956: 303-304).

Son numerosos los ejemplos de plurilingüismo en el teatro cómico del final de la Edad Media. El latín macarrónico aparece esencialmente en las farsas de estudiantes, como la de Maître Mimin étudiant. En la Sottie des copieurs et lardeurs, se satiriza la figura del que emplea un número desorbitado de latinismos, desfigurando su lengua. Otras farsas introducen pequeños toques dialectales, como medio de caracterización social de algunos personajes: el habla dialectal connota siempre a un personaje de baja extracción social $^{10}$.

Otros textos utilizan como rasgo cómico la deformación del francés en boca de extranjeros, especialmente de ingleses. En la rama I b del Roman de Renart (fines del siglo XII), Renart se disfraza de juglar inglés y remeda su manera de hablar ${ }^{11}$. En otros casos se representa no un habla fingida sino el habla real de los ingleses, como el personaje de Gloucester en Jehan et Blonde (1230) de Philippe de Rémi, señor de Beaumanoir, o el rey Enrique III y su séquito inglés en el Mystère de Saint-Louis ${ }^{12}$.

Al final de la Edad Media, en su búsqueda de una lengua noble y cuidada, los llamados grands rhétoriqueurs, como Jean Molinet, multiplican los latinismos en sus poemas. A ello habría que añadir los sermones bilingües, documentados desde fines del siglo X, que alcanzan su máxima difusión a fines del siglo XV e inicios del siglo XVI. Dan lugar a los sermones jocosos, en los que la cita de autoridad, en latín, es aplicada a situaciones humildes, provocando un contraste cómico.

Así, el final de la Edad Media y el Renacimiento son momentos particularmente fecundos en textos políglotas (Lecercle, 1982: 117).

\section{UN SIGLO MARCADO POR LA CUESTIÓN DE LA LENGUA}

En el siglo XVI las cuestiones lingüísticas ocupan un lugar capital: el francés, vulgar antaño menospreciado, se dota de gramáticas capaces de elevarlo al nivel de las lenguas clásicas. La preocupación esencial de la mayoría de los escritores es el enriquecimiento del francés. Para ello se aceptan los préstamos de las lenguas clásicas, pero también las formas dialectales. Rabelais practica este enriquecimiento del francés por medio de formas procedentes de diversos dialectos de ö̈l, no para reflejar un particularismo local de un personaje dado, no para dar «color local» a su texto, sino como medio para mostrar la abundancia del vocabulario francés y su riqueza léxica y sinonímica. La Pléiade recomendará también recurrir a estas formas dialectales, así como los teóricos como Peletier du Mans. Incluso se indica que ciertas voces dialectales, por ejemplo ciertos picardis-

${ }^{10}$ Cf. Chevaldin, 1903: 49-60; Garapon, 1957: 16-35; Zumthor, 1960; Lejeune, 1961; Lewicka, 1961; Garavini, 1978; Renzi, 1993; Revol, 1999; Dull, 1996-1997; Molle, 2002; etc.

${ }^{11}$ No es el único ejemplo de plurilingüismo de la vasta saga cómica del zorro. En la rama $\mathrm{V}$ a, el camello lombardo, legado del Papa, habla en una jerga italo-franco-latina y en la rama VI un personaje, que viene del Limousin, entremezcla voces de su región (cf. Batany, 1992: 87-88).

${ }^{12}$ Cf. Langlois, 1893; Matzke, 1905: 53; Tomiche, 2001: 7; Morais, 2004; Martineau, 2011; Jeay, 2008 ; etc. 
mos, están más próximos a las voces originales latinas que los términos franceses, como hace Jacques Dubois (Sylvius, In linguam Gallicam Isagwge, 1531), o que conservan trazas de la pureza de la lengua francesa, como dirá a finales de siglo Étienne Pasquier (Huchon, 1995: 23). En realidad, los eruditos insisten en la proximidad entre el francés y el griego, ya que, comparado con el latín, el francés quedaría en inferioridad frente al italiano y al español, y es momento de gran rivalidad lingüística. Así se establece un paralelismo entre los dialectos griegos y los dialectos franceses, por lo que las voces dialectales son aceptadas por los mejores escritores. Solo en el siglo XVII, con Malherbe y posteriormente con Vaugelas, se impondrá el mito del «buen uso», basado en el habla de la corte y de las clases acomodadas y de los «cultos» de la capital ${ }^{13}$.

El plurilingüismo aparece fundamentalmente en la poesía cómica y en la satírica. Lo encontramos así en los seguidores de Rabelais: Bonaventure des Périers, Noël du Fail, Jacques Yver, Nicolas de Cholières, Bénigne Poissenot, Étienne Tabourot des Accords, etc. Figura igualmente en los panfletos y en las sátiras: en la Confession catholique du sieur de Sancy y en las Aventures du baron de Foneste d'Agrippa d'Aubigné, en la Satyre Ménippée de la vertu du catholicon d'Espagne et de la tenue des États de Paris, etc. ${ }^{14}$ Las Guerras de Religión son la ocasión para los únicos poemas cultos macarrónicos franceses del siglo XVI, prescindiendo de los textos macarrónicos provenzales escritos y publicados en los años 1520-1530 ${ }^{15}$. Rémi Belleau describe los horrores de la guerra civil en su Dictamen metrificum de bello huguenotico et reistrorum piglamine ad solades, poema en hexámetros dactílicos escrito en los años 1560 y publicado en 1573. Unos años después, en 1588, apareció la Cagasanga, obra inspirada en la anterior y también dedicada a las guerras deG. Su autor parece ser Étienne Tabourot (Cf. Primot, 2011).

Mención aparte merece la comedia humanista, toda ella también posterior a la obra de Rabelais ${ }^{16}$. Solo ocasionalmente encontramos ejemplos de plurilingüismo, esencialmente por influencia italiana, en las comedias francesas de la segunda mitad del siglo XVI. El fanfarrón italiano Panthaléoné de Les Ébahis (1561), de Jacques Grévin, habla en ocasiones en italiano ${ }^{17}$. En Les Napolitaines (1584), de François d'Amboise, el aún más fanfarrón español dom Dieghos jura en español, lo que reproduce e imita el gorrón Gaster, y presenta sus divisas en esta lengua, mientras que la criada Beta introduce un refrán en italiano ${ }^{18}$. Les Écoliers (1589), de François Perrin, presentan un ejemplo de imitación del dialecto del Morvan y del Macônnais ${ }^{19}$. Pierre de Larivey publicó en 1576 y 1611, respectivamente, dos volúmenes de adaptaciones de obras italianas. Introdujo en

${ }^{13}$ Esta ausencia de una norma única, basada en el habla culta parisina, es probablemente la razón principal por la que numerosos autores francófonos contemporáneos se consideran herederos de Rabelais. En efecto, Rabelais es el ejemplo de un gran escritor no sometido a una norma única y estricta, basada en el habla culta parisina. No hay que olvidar, sin embargo, que Rabelais no pretende escribir en un francés dialectal, sino que pretende ampliar la lengua literaria francesa, en un momento en el que la norma no estaba fijada, para incluir numerosos términos de otros dialectos de oïl.

${ }^{14}$ Chevaldrin, 1903: 62-63; Garavini, 1978: 71-72; Kötler, 1995; etc.

15 Cf. posteriormente n. 51.

${ }^{16}$ Étienne Jodelle hizo representar, ante el Rey, la primera tragedia francesa y la primera comedia a principios de 1553 y Rabelais falleció a principios de marzo de ese mismo año.

17 II, 3 y V, 1. Aa.Vv., 1972, IV: 261-262 y 312-313.

18 I, 3; I, 4; III, 6; V, 10 y 12. Aa.Vv., 1873, I: 357, 362, 391, 421 у 426.

19 IV, 4. Aa.Vv., 1873, I: 474-475. 
la escena francesa la figura del pedante, es decir del «pedagogo», profesor y educador, que alardea de su erudición e introduce en su discurso frases latinas o multiplica los latinismos ${ }^{20}$, en sus obras Le Laquais (1579), La Constance (1611) y Le Fidèle (1611) ${ }^{21}$.

Una obra publicada a finales del siglo, La Tasse, presenta, sin embargo, el ejemplo más extremo de plurilingüismo en la escena francesa. En ella, algunos personajes hablan francés, otros provenzal y el amante de la mujer italiano. Esta «comedia» es, en realidad, una farsa alegre y picante, compuesta en octosílabos (metro preferido por la vieja farsa), aunque dividida en cinco actos. En ella el plurilingüismo no tiene una función cómica, sino que, destinada a un público meridional, refleja la situación de diglosia que vivía el sur de Francia, donde coexistían el francés y el occitano, además del latín, lengua de cultura ${ }^{22}$.

\section{RABELAIS, «UNA PRODIGIOSA EXCEPCIÓN» ${ }^{23}$}

Probablemente en $1532^{24}$ apareció, en Lyon, el primer volumen de su saga de gigantes, Pantagruel. Les horribles et espovantables faictz et prouesses du tresrenomme Pantagruel Roy des Dipsodes filz du grant geant Gargantua. Composez nouvellement par maistre Alcofrybas Nasier ${ }^{25}$. Rabelais reside entonces en la ciudad del Ródano donde ese mismo año de 1532 publica obras eruditas de medicina y derecho ${ }^{26}$ y el 1 de noviembre es nombrado médico del Hôtel-Dieu. No ha realizado todavía su primer viaje a Italia, ni entrado en contacto con Jean Du Bellay, desde septiembre de ese mismo año obispo de París, que realiza misiones diplomáticas en Roma al servicio de Francisco I y que se convertirá en su protector. Es decir, carece todavía de contactos con la corte francesa y su conocimiento del mundo renacentista italiano es meramente libresco.

Bajo el título engañoso que establece una aparente filiación con unas obras populares, las crónicas gargantuinas, publicadas por esos años, la obra es un relato esencialmente cómico que se dirige a un público culto de humanistas y estudiantes, el único capaz de comprender sus numerosas alusiones y sus juegos con las lenguas.

Rabelais utiliza la mayoría de los juegos plurilingües que empleará a lo largo de toda su obra, aunque en obras posteriores les añada funciones como el «efecto de realidad», desconocido en esta primera obra.

\footnotetext{
${ }^{20}$ Inauguró la figura del pedante como tipo cómico, en Italia, Francesco Befo, con su pieza Il Pedante, publicada en 1529 (MacPhail, 2008: 880).

${ }^{21}$ Le Laquais, AA.VV., 1972, V: 7-401; La Constance, AA.VV., 1972, VI: 191-302; Le Fidèle, AA.VV., 1972, VI: 303-486. No es, sin embargo, el habla profundamente latinizada y «entreverada» con voces y frases latinas del pedante, personaje secundario esencialmente cómico y ridículo, el único ejemplo de plurilingüismo en el autor. En le Laquais, el italiano Horacio pronuncia un dicho en español (III, 2. AA.VV., 1972, V: 56). En Les Esprits, el brujo M. Josse hace un conjuro ininteligible con resonancias latinas (III, 2. AA.VV., 1972, V: 242). El médico, M. Théodore, pronuncia una frase en latín en Les Écoliers (II, 4. AA.VV., 1972, VI: 125). A ello habría que añadir las expresiones procedentes de oraciones religiosas en latín, etc.

22 Recueil de pièces rares et facétieuses, III, 1873: 1-161.

${ }^{23}$ Garavini, 1978: 69: «nella storia letteraria francese, una mostruosa eccezione».

${ }^{24}$ No sabemos con seguridad cuándo se publicó la obra, ya que la más antigua edición conservada, publicada por Claude Nourry, carece de fecha.

${ }_{25}$ Anagrama de Françoys Rabelais.

${ }^{26}$ Aunque el Cuspidii Testamentum, del que da una edición, sea un conjunto de dos falsificaciones italianas, entonces consideradas auténticas, pues la superchería no se descubrió hasta 1587.
} 
Lleva hasta sus últimas consecuencias los procedimientos empleados en la literatura francesa del final de la Edad Media ${ }^{27}$. La influencia italiana, importante en el tema del plurilingüismo, es mucho más evidente a partir del segundo libro publicado, el Gargantua, aunque ya al redactar el Pantagruel conocía obras como el Baldus de Folengo.

\subsection{La yuxtaposición de códigos}

Era frecuente en una época de diglosia entre el latín (única lengua de la enseñanza) y la lengua vulgar (el francés y en el sur el francés y el occitano), citar en latín los títulos de obras latinas e incluso griegas, e introducir numerosas voces, sintagmas u oraciones en latín dentro de un texto en vulgar:

comme Senecque narre au quart livre questionum naturalium, parlant de l'origine et source du Nil (Cap. 2. Rabelais, 1994: 224).

Puede tratarse de una cita de «autoridad», en algún caso traducida inmediatamente como en la siguiente alusión al Arte poética (v. 9. 2002: 181) de Horacio:

Et demandoit la cause de ce, les chanoines dudict lieu luy dirent que n'estoit aultre cause sinon que Pictoribus atque poetis etc. c'est à dire que les Painctres et Poetes ont liberté de paindre à leur plaisir ce qu'ilz veullent. (Cap. 5. Rabelais, 1994: 230).

En ocasiones alternan la denominación vulgar, en francés, y la denominación culta en latín:

bruslant une grande partie du ciel, que les philosophes appelent uia lactea: et les Lifrelofres nomment le chemin sainct Jacques. (Cap. 2. Rabelais, 1994: 223).

Una yuxtaposición de códigos lingüísticos, trivial y frecuente en la época, puede cobrar un sentido cómico cuando una frase bíblica o litúrgica se inserta en un contexto jocoso o bien cuando se deforma la cita para darle un tono burlesco.

Así, quod vidimus testamur («damos fe de lo que hemos visto». Rabelais, 1994: 215) es una cita del Evangelio de san Juan $(3,11)$ que atestigua la veracidad de lo relatado. Cobra un tono lúdico y paródico al atestiguar, en el Prólogo de la obra, la autenticidad de un relato tan inverosímil como el que presenta el narrador Alcofrybas Nasier.

El procedimiento era conocido en la época y había sido abundantemente explotado por los sermones jocosos, como también la deformación de fórmulas del latín eclesiástico. Las palabras del Credo, Patrem Omnipotentem, se convierten en Ventrem omnipotentem (Cap. 1. Rabelais, 1994: 218), al describir los efectos que producía en las gentes de los primeros tiempos el comer unos nísperos maravillosos: unos se hinchaban por el vientre, otros por la espalda, etc. En otros casos, se introduce un juego de palabras entre una voz francesa y una voz latina. Siguiendo con la relación de los prodigios producidos por los gordos nísperos, a otros les crecía extraordinariamente la nariz: «Nason, et Ovide en prindrent leur origine. Et tous ceulx desquelz est escript: Ne reminiscaris» (Cap. 1. Rabelais, 1994: 219). Después de transformar jocosamente Ovidio Naso en dos persona-

${ }^{27}$ Hay que tener en cuenta que lo que suele llamarse «teatro medieval» se prolonga a lo largo de la primera mitad del siglo XVI y que Rabelais participó incluso en la representación de una farsa en sus tiempos de estudiante de Medicina en Montpellier, según nos cuenta en el Tiers livre, cap. 34 (Rabelais, 1994: 460). 
jes diferentes ${ }^{28}$, introduce el principio de la antífona cantada antes y después de los siete salmos de la Penitencia: Ne reminiscaris [delicta nostra] («No tomes en consideración [nuestras faltas]»), para introducir un juego de palabras entre el latín ne y el francés nez (pronunciado [ne]), partiendo de la idea, muy extendida en la época, de que una gran nariz es síntoma de una gran potencia viril, creencia popular que rebatiría unas décadas después el célebre médico Laurent Joubert ${ }^{29}$. La broma era tradicional y había dado lugar al Dicté joyeux des Noms de tous les nez $z^{30}$.

Esta broma, tradicional en los medios estudiantiles y clericales, recoge el procedimiento de la superposición de códigos, aunque aquí reducido a una única palabra. El resultado es un enunciado equívoco, con un sentido diferente en latín y en francés, basado en la homofonía entre el latín ne y el francés nez. En el Gargantua, Rabelais recogerá este mismo procedimiento en un enunciado más extenso con doble lectura en latín y en francés ${ }^{31}$.

El latín permite también introducir una contrepèterie, juego lingüístico que consiste en la inversión o transposición de una sílaba o fonema entre dos palabras, o de dos palabras, dentro de una misma oración, de lo que resulta un enunciado totalmente diferente. En la serie de coq-à-l'âne ${ }^{32}$ que constituye el pleito entre los señores de Baisecul y de Humevesne (extraordinario ejemplo de desarticulación del código lingüístico hasta llegar a la incoherencia semántica), se introduce una contrepèterie que deforma un dicho latino: Non de ponte cadit qui cum sapientia uadit ( «No cae del puente quien anda con prudencia») se convierte en «non de ponte uadit qui cum sapientia cadit» («no anda del puente fuera quien con prudencia cae». Cap. 11. Rabelais, 1994: 256) al invertirse uadit y cadit $^{33}$. También puede fragmentarse un término, intercalando otro

${ }^{28}$ Personaje atraído por el parecido entre Naso y nasus «nariz».

29 «Et quoy qu'on dise, ad forman nasi, cognoscitur ad te leuaui, d'autant que la proportion des membres n'est obseruee en tous, plusieurs ont vne belle trompe de nez, qui sont camus dans la brayette: \& plusieurs camus de nez, sont bien appointez du principal outil» (V, 4. Joubert, 1586: 477).

${ }^{30}$ Publicado por Schwob, 1903.

${ }^{31}$ El jovial y poco refinado monje, Frère Jean, cita una frase del Breviario inspirada en un versículo de Isaías (XI, 1) que anuncia la venida de Cristo: «Germinavit radix Jesse. Je renye ma vie je meurs de soif» (Gargantua, cap. 39. Rabelais, 1994: 109). La frase francesa explica el sentido que quiere darle el voraz monje: una metástasis de $m$ y $n$ transforma germinavit en gernimavit, es decir, «je renie ma vie» («reniego de mi vida») y Jessé equivale a «j'ai soif» («tengo sed»), puesto que soif se pronunciaba en la época [se]. Estos juegos son particularmente frecuentes en la literatura española de los siglos XVI y XVII, con enunciados mucho más largos, debido a la mayor proximidad entre el español y el latín que entre el francés y la lengua de la antigua Roma. Bastaría recordar la «Epístola latina e hispánica» publicada al final de la Vtil y breve institvtion para aprender los principios y fundamentos de la lengua hespañola, gramática española al uso de los extranjeros publicada en Lovaina, en 1555: «Scribo \& supplico rogando te Francia des \& respondeas tales probationes, tractando de tua eloquentia, loquela \& excellentia, quales scribo de Hispania: comparando gentes, nationes \& prouincias: quales manifesto dictando epistolas puras, Latinas \& Hispanas. Hispania (antiquissima corona) perseuero (cessante memoria de contrario) duro, \& regno prouincia Christiana. Tu Francia principias à Moroueo, \& regnas continuando quasi mille annos christiana, prædicante sancto Remigio \& regnando Clodoueo. Et Hispania quasi ante quatercentum annos prædicante sancto Iacobo Apostolo [...]» (1977: 125-126, 125). Se volvió a imprimir, con variantes, en las Alabanzas de las lenguas hebrea, griega, latina, castellana y valenciana de Rafael Martín de Viciana (1574). Étienne Tabourot dedica un capítulo a los «equivoques du Français au Latin» (Cap. V. Tabourot, 1986, I: 43 r-v).

32 Juego verbal, puesto de moda por esos años por el poeta Clément Marot y heredero de la vieja fatrasie medieval, que consiste en una serie de oraciones que carecen de sentido a pesar de estar construidas según las reglas sintácticas de la lengua. En ocasiones pueden tener un sentido satírico que se nos escapa.

${ }^{33}$ En esta misma obra, Rabelais introduce dos otras contrepèteries ajenas al plurilingüismo, a las que llama antistrophe: 
entre sus dos partes, como en la expresión empleada poco después: «Et en croy partie adverse in sacer uerbo dotis» (Cap. 11. Rabelais, 1994: 256) es una deformación jocosa de in verbo sacerdotis («en palabra de sacerdote». «Creo a la parte contraria in sacer uerbo dotis»).

El empleo del griego es muy raro en esta obra. Se reduce a algún título de libro, como el apócrifo peri grammaton acriton atribuido a Zoroastro («Sobre las letras difíciles de discernir». Cap. 24. Rabelais, 1994: 300), o bien libros existentes que alternan con otros que no lo son:

Les livres de Artemidore peri onirocriticon.

De Anaxagoras peri semion.

D'Ynarius peri aphaton.

Les livres de Philistion.

Hipponax peri anecphoneton, et un tas d'aultres, tant que Panurge luy dist. (Cap. 18. Rabelais, 1994: 284) ${ }^{34}$.

A ello habría que añadir una invocación en griego, considerada un exorcismo contra los diablos ${ }^{35}$, en el jocoso relato de la rocambolesca huida del charlatán Panurgo de Turquía: «agyos, athanatos, ho theos» («Dios es santo e inmortal». Cap. 14. Rabelais, 1994: 265).

En todos los casos el griego aparece transcrito en caracteres latinos. Los caracteres griegos solo aparecen, en diversas ocasiones, a partir de la obra siguiente ${ }^{36}$.

El hebreo apenas si está presente en el conjunto de la obra de Rabelais, salvo bajo la forma de nombres propios (antropónimos y topónimos) en el Quart livre. Pero en este primer libro, Rabelais alude a algunos rasgos gramaticales ${ }^{37}$ y ortográficos ${ }^{38}$ de la lengua que, para muchos contemporáneos, era la lengua hablada en el Paraíso. Además, incluye la única frase en hebreo de toda su obra: Lamah hazabthani, últimas palabras de Cristo en la Cruz, aunque en realidad pronunciadas no en hebreo sino en arameo (Mateo, 27, 46 y Marcos, 15, 34).

car il disoit qu'il n'y avoit q'un antistrophe entre femme folle à la messe, et femme molle à la fesse. (Cap. 16. Rabelais, 1994: 274).

- Mais (dist il) equivocquez sur À beaumont le viconte.

- Je ne sçauroys, dist elle.

- C'est (dist il) À beau con le vit monte. (Cap. 21. Rabelais, 1994: 293).

Estos ejemplos responden al gusto por los equívocos picantes, muy extendido en el siglo XVI en Francia.

${ }^{34}$ La comicidad de esta enumeración radica en alternar libros existentes (como Sobre la significación de los sueños de Artemidoro) con obras y autores inventados por Rabelais (como Sobre las cosas indecibles de Inario) o atribuir a autores que existieron obras que nunca compusieron (Sobre las cosas que hay que callar de Hiponax), etc.

${ }^{35}$ Incipit de una oración de Viernes Santo.

${ }^{36}$ ¿Puede deberse al editor de la primera edición, Claude Nourry, especializado en obras no de gran envergadura (libros de caballería, calendarios de pastores, traducciones francesas de novelas latinas, italianas y españolas, tratados de piedad, etc. [Defaux, 1977: 77])? Rabelais no lo modificó, sin embargo, en ediciones sucesivas. La obra siguiente, el Gargantua, fue publicada por otro editor, probablemente por François Juste, también en Lyon. Es imposible afirmarlo con seguridad, ya que el único ejemplar conocido de la primera edición carece de portada.

${ }^{37}$ El utilizar en latín el futuro como imperativo, siguiendo el ejemplo del hebreo, según declara, permite a Panurgo robar con buena conciencia, en las iglesias, el dinero del cepillo de los buleros (Cap. 17. Rabelais, 1994: 278)

${ }^{38}$ Ausencia de vocales en la escritura hebrea (Cap. 23. Rabelais, 1994: 299). 
El episodio se sitúa en Honfleur, cuando Pantagruel y los suyos esperan un viento propicio para embarcar hacia su país de Utopía, invadido por los dipsodas. El protagonista recibe un anillo de oro de una dama de París, a la que acaba de abandonar sin despedirse, con esta inscripción hebrea y un diamante sin facetas. El sabio Epistemon traduce la inscripción, lo que permite al ingenioso Panurgo interpretar el mensaje: «Dy amant faulx: pourquoi me as tu laissée?»(Cap. 24. Rabelais, 1994: 301), deshaciendo el jeroglífico (rébus) ${ }^{39}$ que tanto había hecho cavilar a los compañeros.

Es bien conocido el interés de Rabelais por el hebreo, aunque se ignora el conocimiento que logró tener de esta lengua. La anécdota anterior nada prueba en cuanto a su dominio de la lengua hebrea, puesto que procede de la novela corta XLI de Il novellino de Masuccio Guardati, llamado el Salermitano, obra publicada póstumamente en $1476^{40}$.

Fuera de la exhibición de poliglotismo de Panurgo, la inserción de enunciados en lenguas modernas es muy rara en esta obra. El occitano queda reducido al episodio del escolar limosín, cuando el gigante le obliga a hablar «de forma natural» (Cap. 6. Rabelais, 1994: 234). En cuanto a las lenguas extranjeras, cabría recordar una expresión alemana, en el ininteligible proceso de Baisecul y Humevesne, atraída por la mención anterior a los alemanes:

Mais le grand diole y eut envie: et mist les Allemans par le derriere, qui firent diables de humer her tringue, tringue, de doublet en case (Cap. 12. Rabelais, 1994: 259).

Recoge la exclamación favorita de los lansquenetes, que se convertirá en leitmotiv de la obra hasta la «revelación» final de la divina Botella, trinch.

Tampoco el italiano está muy presente. Panurgo emplea una forma lombarda, añadiendo una terminación italiana a bougre ${ }^{41}$, para dirigirse amablemente a su pachá: «Missaire bougrino tu pers ici ton temps [...]» (Cap. 14. Rabelais, 1994: 265). Una fórmula de disculpa, imitada del italiano («Pardonnante my»), aparece en la despedida del narrador, en el último capítulo de la obra (Cap. 34. Rabelais, 1994: 336).

Frente a esta parquedad de elementos plurilingües, excepto los tradicionales juegos con el latín, destaca la abundancia de lenguas empleadas por Panurgo cuando irrumpe en la obra, quebrando el diseño inicial de la misma ${ }^{42}$.

\subsection{El poliglotismo de Panurgo}

Si la mayoría de los juegos cómicos basados en la yuxtaposición de códigos lingüísticos diferentes, anteriormente vistos, cuentan con precedentes en la Edad Media, lo mismo cabría decir de la profusión de lenguas con las que Panurgo responde, en su primer encuentro, a las preguntas (inspiradas en los encuentros de la Odisea y la Eneida) que Pantagruel le hace, tras manifestarle su gran afecto ${ }^{43}$.

\footnotetext{
39 Los rébus eran un juego muy de moda por entonces.

40 AA.VV, 1993: 158-162. En la novela italiana la frase aparece en arameo.

41 Entonces esencialmente «sodomita».

${ }^{42}$ Todo parece indicar que la aparición de Panurgo, con su discurso políglota, fue añadida después del diseño inicial, ya que la obra, hasta la edición de 1542, constará de dos capítulos IX.

43 «Pourtant mon amy dictes moy qui estes vous, dont venez vous, où allez vous, que querez vous, et quel est vostre nom» (Cap. 9. Rabelais, 1994: 246).
} 
En la más antigua edición conservada, Panurgo, que llega a París herido y maltrecho, retrasa la petición de una ayuda que le es indispensable, respondiendo en nueve lenguas, que Pantagruel y sus compañeros no parecen entender. La edición de 1533 añade el texto escrito en inglés de Escocia y una lengua inventada, la edición de 1534, el texto danés y la de 1542, la última revisada por el autor, el vasco. Esta exhibición de lenguas, en su mayoría incomprensibles para los contemporáneos, tuvo sin duda éxito, puesto que Rabelais aumentó su número de edición en edición, añadiendo lenguas cada vez menos conocidas.

Es, sin duda, el mayor alarde de poliglotismo de la literatura francesa hasta ese momento, pero contaba con precedentes. En la farsa de Maître Pierre Pathelin (vv. 834968. 1970: 45-51), un texto que Rabelais conocía bien puesto que alude a él en diversas ocasiones ${ }^{44}$, el astuto falso abogado finge delirar para engañar al mercader del que se ha llevado fiado una pieza de tela. Habla en diversas lenguas y dialectos franceses (lemosín, picardo, normando y lorenés) y en dos lenguas habladas en territorios limítrofes a los dominios de oïl (el bretón y el flamenco o neerlandés), a las que se añade el latín macarrónico. La función del plurilingüismo en la obra es engañar al acreedor, fingiendo Pathelin una grave enfermedad que le hace delirar y hablar en lemosín, como un tío suyo, en picardo, como su madre, en normando, como su maestro, o en bretón, como su abuela, según declara su mujer Guillemette, etc. A ello se añadía, en la representación, la exhibición de la habilidad del actor capaz de expresarse en diversos idiomas ${ }^{45}$.

Si Panurgo es más hábil que los más hábiles actores del momento, el motivo por el que retrasa una ayuda que le es indispensable dista mucho de ser el engaño. Panurgo busca sorprender con una respuesta opuesta a la que cabría esperar, vista su lamentable situación. Panurgo es el pícaro astuto y trapacero, el embaucador tramposo, fértil en trucos y sobre todo el gran hablador. Se presenta como el gran viajero, a la manera de Ulises (lo que podría explicar sus vastos conocimientos de lenguas, aprendidas, muchas de ellas, a lo largo de sus viajes), y como un ser multiforme, a la manera de un nuevo Proteo. Esta exhibición de sus habilidades lingüísticas muestran al gigante que las leyes de la hospitalidad y de la caridad evangélica exigen ayudar al caminante que llega desvalido antes de interrogarlo. Al mismo tiempo, muestra un rasgo esencial del personaje: su habilidad inigualable en el arte de la palabra, ya sea para engañar a los demás o para divertirlos. Su virtuosismo es tal que no solo domina lenguas extranjeras entonces poco conocidas, sino que es capaz de inventar otras cuya apariencia no desdice de las reales.

Al presentarse, Panurgo no busca comunicarse con Pantagruel y los suyos: su apariencia es un lenguaje suficientemente elocuente para mostrar sus necesidades. De ahí que los compañeros, incluso el más sabio, no reconozcan lenguas tan extendidas entre los humanistas como el italiano e incluso el español (un español, por cierto, bastante «afrancesado»). Es un encuentro sorprendente para preparar la amistad extraordinaria de dos personajes cuyos nombres tienen en común la raíz griega pan «todo».

Panurgo es un excéntrico, pues habla lenguas desconocidas y despreciadas por sus contemporáneos, pero ha llevado hasta sus últimas consecuencias el programa que Gar-

${ }^{44}$ Cf. Cohen, 1956: 313.

45 Así, en la Sottie des Vigiles de Triboulet (Recueil Trepperel, I, 1935: 232, vv. 219-221), se alaba al actor Triboulet por ser capaz de interpretar en latín, en picardo, en flamenco y en francés. 
gantua proponía a su hijo en la carta que le enviaba en el capítulo anterior ${ }^{46}$, aunque desvirtuándolo, ya que prescinde de lenguas consideradas «clásicas» y opta resueltamente por las lenguas modernas.

De las trece lenguas en las que se expresa Panurgo, tres son lenguas imaginarias. Para los primeros lectores, no diferían mucho, salvo en el nombre que les dan los personajes, de lenguas tan poco extendidas como el danés o el vasco. El sabio Epistemon identifica la primera de ellas como la lengua de las antípodas y la segunda como linternés. La tercera es, a decir de Pantagruel, la lengua de su país de Utopía o se le parece mucho. Aunque se han propuesto diversas identificaciones para esas lenguas, habría que considerarlas como un ejemplo más de la creatividad lingüística de Rabelais, que prolonga una vieja tradición que se remonta, al menos, hasta el mundo griego. En los tres casos son lenguas de países inexistentes o cuya situación geográfica está poco definida. Por el contrario, en el relato de su huida de los turcos, Panurgo reproduce una expresión supuestamente en turco: el que lo asaba (como al buen san Lorenzo), al sentir el fuego provocado por Panurgo, «se levant crya a la fenestre tant qu'il peut "dal baroth, dal baroth", qui vault autant à dire comme "au feu, au feu"» (cap. 14. Rabelais, 1994: 264). Aunque el empleo de lenguas imaginarias que se hacen pasar por lenguas auténticas contaba también con precedentes medievales franceses ${ }^{47}$, Rabelais inaugura la moda de la falsa lengua turca que reaparecerá en la comedia del siglo XVII, en La Scur de Rotrou o en Le Bourgeois gentilhomme de Molière ${ }^{48}$.

\subsection{Las lenguas mixtas. La mezcla de lenguas}

Si las frases o expresiones latinas insertadas en el texto francés responden a un hábito de la época, pero pueden adquirir una función cómica al ser deformadas o aparecer en un contexto insólito, suscitando la sorpresa y la hilaridad, otra fuente de comicidad puede ser la mezcolanza de lenguas. El empleo de una lengua «híbrida» adopta dos posibles formas en el Pantagruel: la mezcla de latín y de francés o la deformación del francés en boca de un extranjero, es decir, la mezcla de francés y de la lengua materna del foráneo. Ambos procedimientos contaban con precedentes medievales.

El latín macarrónico consiste en una traducción literal del francés al latín. Es una deformación del latín por influencia del francés. La sintaxis es francesa, así como gran parte del léxico, al que se dan terminaciones latinas. Supone un insuficiente conocimiento del latín o bien es una broma de estudiantes. Es un latín deformado, propio, en las

${ }^{46}$ En ella le exhortaba a aprender perfectamente el griego, el latín, el hebreo, el caldeo (es decir, el arameo) y el árabe (Cap. 8. Rabelais, 1994: 244).

${ }_{47}$ También, en el Infierno de Dante, Pluto lanza una frase en una lengua incomprensible (canto VII, v. 1. 1994, II: 109), así como posteriormente Nemrod (canto XXXI, v. 67. 1994, II: 533). En ambos casos se ha intentado identificar dichas lenguas sin resultados convincentes.

${ }^{48}$ En realidad, en la Edad Media europea habían aparecido los dos tipos de lenguas inventadas, a las que Schnapp (1990: 178-179) llama «expresivas» y «analíticas». Las primeras son lenguas que carecen de sentido. A este grupo pertenecen todos los ejemplos del Pantagruel y, en general, de Rabelais. Los lenguajes analíticos son, en cambio, propuestas de lenguas que aspiran a paliar los «defectos» de las lenguas naturales (equívocos, arbitrariedad, irregularidades, etc.): son las lenguas presentadas, por ejemplo, en las utopías francesas del siglo XVII y a este tipo responde igualmente el esperanto, pero también la lingua ignota que Hildegarda de Bingen, abadesa de Rupertsberg, elaboró a mediados del siglo XII. 
farsas medievales, de estudiantes de escasas luces, como en la farsa de Maître Mimin, l'étudiant. Posteriormente aparece sobre todo en el habla de pedantes y médicos. Es fácil de entender, de ahí su relativa frecuencia en el teatro cómico. Este latín degradado, contrario a la búsqueda humanista de la pureza del latín clásico, está bien documentado en el Pantagruel. Aparece algún ejemplo en el lenguaje incoherente del pleito entre Baisecul et Humevesne: «Beati lourdes quoniam ipsi trebuchauerunt» (Cap. 11. Rabelais, 1994: 255); «et bevez à oultrance: depiscando grenoillibus» (Cap. 12. Rabelais, 1994: 259). Panurgo pronuncia alguna frase documentada en la jerga estudiantil de la época:

Lors dist Pantagruel. «Comment scez tu que les membres honteux des femmes sont à si bon marché: car en ceste ville il y a force preudes femmes, chastes et pucelles.

- Et ubi prenus? Dist Panurge. Je vous en diray non oppinión, mais vraye certidude et asseurance. (Cap. 15. Rabelais, 1994: 271) ${ }^{49}$.

Sobre todo, el latín macarrónico es particularmente frecuente en la burlesca relación de los títulos de los libros conservados en la biblioteca de Saint-Victor de París: «Decretum uniuersitatis Parisiensis super gorgiasitate muliercularum ad placitum»; «Ars honeste pettandi in societate per M. Ortuinum»; «De brodiorum usu et honestate chopinandi, per Siluestrem prieratem Tacospinum», etc. (Cap. 7. Rabelais, 1994: 236).

Como en las Epitola obscurorum virorum, el latín degenerado permite, en algún título de esta insólita relación, burlarse de los teólogos de Colonia, adversarios de Reuchlin. Este latín bastardo tiene una función esencialmente satírica, como lo tendrá en la arenga de Janotus de Bragmardo del Gargantua (Cap. 19) ${ }^{50}$.

No existe, en cambio, ningún ejemplo de macarronea o macarrónico literario, género típicamente italiano, del que el mejor representante es Teófilo Folengo. Consiste en crear una lengua híbrida y artificial, dando terminaciones latinas a voces italianas y utilizar el marco del hexámetro y del pentámetro clásico. Es decir, se deforma la lengua latina introduciendo voces y expresiones de la lengua vulgar latinizadas, pero se conserva la sintaxis y la métrica latinas. El procedimiento es muy raro en Francia ${ }^{51}$, Rabelais solo presenta un ejemplo de este macarrónico literario en el Quart libre (Cap. 13. Rabelais, 1994: 569) $)^{52}$.

Opuesta al latín macarrónico es la jerga de los écumeurs, écorcheurs o despumeurs de latín, de la que Rabelais nos ha dejado una imagen inolvidable en el escholier Limosin (Cap. 6. Rabelais, 1994: 232-235). La morfología y la sintaxis son francesas, pero se multiplican los términos latinos. Es la tendencia, ya presente en los grandes retóricos,

\footnotetext{
${ }^{49}$ Cohen (1956: 312) considera posible, aunque no seguro, que este ejemplo proceda de la Farce de Colin.

${ }^{50}$ Esta lengua híbrida conservó cierta boga hasta principios del siglo XX como diversión académica (Forster, 2009: 15-16).

${ }^{51}$ Además de los dos poemas, a los que se aludió anteriormente, el primero de Rémi Belleau y el segundo probablemente de Étienne Tabourot, dos autores del Sur de Francia publicaron unos años antes textos en los que se mezclan latín, provenzal y francés: Ad suos compagnones studentes (primera edición fechada, 1529) y la Meyra entrepriza catoliqui Imperatoris (1536) de Antoine Arena y la Historia bravissima Caroli Quinti Imperatoris (1536) de Jean Germain. Estos dos últimos textos cuentan la desastrosa campaña de Carlos V en Provenza, durante el verano de 1536. Basándose en la primera obra de Arena, Lazzerini (1982: 13) sostiene que la poesía macarrónica provenzal sería un producto autóctono, independientemente del ejemplo de Folengo. Cf. también, Primot, 2011.

52 Sin embargo, Rabelais conocía y admiraba a Folengo, al que cita bajo su seudónimo de Merlín Cocaio, ya en el Pantagruel (Cap. 1 y 7. Rabelais, 1994: 220 y 241).
} 
a enriquecer el francés mediante préstamos latinos, llevada hasta el extremo. Por otra parte, la figura del escumeur de latin era ya, por esos años, una figura tradicional. Ya Geoffroy Tory (1529) la había criticado, en el prólogo a su tratado tipográfico («Aux Lecteurs de ce Present Liure»), reproduciendo paródicamente un párrafo que Rabelais toma casi literalmente en la intervención del escolar lemosín.

La originalidad de Rabelais está en haber inventado una anécdota en la que insertar la frase de Tory y haber elegido como protagonista al pobre provinciano, al lemosín que, llegado a París, es incapaz de expresarse correctamente en la lengua de la capital e intenta compensarlo recurriendo a voces de la lengua oficial de la Universidad, el latín, en su afán por remedar el habla culta parisina. El tipo del provinciano era ya, de por sí, cómico. A ello se añade fundamentalmente la profunda distorsión entre una forma rebuscada y un fondo que solo transmite las farras y francachelas estudiantiles de jóvenes muy poco dados al saber. Lo narrado convierte en grotesco el lenguaje que, en tono serio, había empleado Francesco Colonna en su Hypnerotomachia Poliphili (1499) ${ }^{53}$. Este intento de crear un «vulgar ilustre» queda desacreditado en boca del liviano escolar. Pese a ello, Rabelais comparte la pretensión de enriquecer la lengua francesa y de acrecentar la elegancia del vernáculo. Es más, no vacila en emplear algún término del pobre y ridículo escolar. Pero entendió la fuerza cómica de esta tendencia llevada a sus extremos, sobre todo si se ponía en boca de un personaje esencialmente ridículo, ya que reunía a la vez la consideración adversa del provinciano incapaz de expresarse correctamente en la lengua de la capital, del pedante y del estudiante de escasas luces.

La misma mezcla de dos lenguas, tomando elementos fonéticos, morfológicos, sintácticos y léxicos de una u otra lengua, pero en este caso de forma involuntaria, aparece en el habla de los extranjeros. Tanto si un extranjero tiene un habla con rasgos aberrantes, como si un personaje remeda su lengua, el procedimiento es antiguo y ha sido siempre fuente de una comicidad basada en cierto complejo de superioridad frente al foráneo. En el Pantagruel únicamente aparece una vez y la obra completa solo cuenta con un segundo ejemplo en el Quart libre (Cap. 53). En ambos casos se trata del remedo de este habla defectuosa. En el ejemplo del Pantagruel, además, a la mofa del habla de los foráneos, se une un equívoco picante. Entre las lenguas que habla, en su primera aparición, Panurgo figura el «escocés», es decir, el inglés hablado en los Lowlands de Escocia y no el gaélico. Carpalim lo reconoce y exclama: «Sainct Treignan foutys vous descoss, ou j'ay failly à entendre» (Cap. 9. Rabelais, 1994: 247). La deformación de vous êtes en foutys vous, además de remedar el habla de los escoceses de la Guardia Real francesa, permite introducir un equívoco picante con el verbo foutre («joder»).

\section{Conclusión}

En esta primera obra publicada de la saga de los gigantes, Rabelais multiplica los ejemplos de juegos con el plurilingüismo. No en balde, este texto, un tanto provinciano, anterior a los contactos de Rabelais con el embajador de la corte francesa ante Roma,

${ }^{53}$ Aunque es probable que Rabelais no conociese todavía esa obra en los tiempos en los que preparaba la primera edición de su Pantagruel. 
Jean Du Bellay, y de su primer viaje a Italia, encierra los dos episodios de plurilingüismo más célebres de toda su obra, el episodio del escolar lemosín y la extraña irrupción de Panurgo en la obra, hablando numerosas lenguas que Pantagruel y sus compañeros no logran comprender, aunque identifiquen algunas de ellas.

En el Pantagruel, el empleo de las lenguas y dialectos no responde, en general, a un deseo de caracterizar regional y socialmente a los personajes, sino que tiene una función humorista, suscita la extrañeza, y muestra la habilidad del autor para jugar con las posibilidades expresivas del lenguaje. Es fundamentalmente un juego de humanista que busca sorprender y provocar la risa, cuando no responde a una costumbre de una época habituada a una constante diglosia, lo que explica la frecuente presencia de formas latinas en los discursos romances. A estas funciones lúdica y cómica esenciales, se añade en algún caso una función satírica, mostrando, por ejemplo, por medio de una frase en latín macarrónico, la supuesta ignorancia de los teólogos de Colonia, en algún título de la biblioteca de Saint-Victor de París.

El plurilingüismo tiene en esta obra una función fundamentalmente cómica, en algún caso unida a la explotación de un tópico tradicional, como en el episodio del lemosín ridículo, al que el obligado empleo de su lengua materna desenmascara. La presencia del occitano tiene entonces también una función realista, pero, salvo en este ejemplo, las lenguas extranjeras o regionales no aparecen en boca de personajes oriundos de estas regiones, como aparecerá posteriormente en el episodio del gascón que perdió su dinero y, enfurecido, provocó a batirse a los lansquenetes, que replicaron en su lengua (Tiers livre, cap. 42. Rabelais, 1994: 484-485) ${ }^{54}$. El plurilingüismo tiene aquí una función evocativa y realista, además de cómica y satírica, al remitir a las connotaciones culturales peyorativas asociadas a los nativos de diversas regiones o países.

\section{BiBLIOGRAFÍA}

AA.VV. (1873). Le théâtre français au XVI et XVII siècle ou Choix des comédies les plus remarquables antérieures à Molière. I. Édouard Fournier (ed.). París: Laplace, Sanchez et Cie.

AA.VV. (1972). Ancien théâtre françois ou Collection des ouvrages dramatiques les plus remarquables depuis les mystères jusqu'à Corneille. IV, V, VI y VII. Viollet le Duc (ed.). Nendeln (Liechenstein): Kraus reprint. (Facsímil de la ed. de 1855).

AA.VV. (1993). Conteurs italiens de la Renaissance. Giancaro Mazzacurati (pref.) y Anne MotteGillet (ed.). París: Gallimard, «La Pléiade».

ARISTófanes (1972-I969-I967). I. Les Acharniens. Les Cavaliers. Les Nuées. 10a reimpr., rev. y corr. 1972. II. Les Guêpes. La Paix. $6^{a}$ reimpr., rev. y corr. 1969. III. Les Oiseaux. Lysistrata. $7^{\mathrm{a}}$ reimpr., rev. y corr. 1967. IV. Les Thesmophories. Les Grenouilles. $6^{\mathrm{a}}$ reimpr. 1967. Victor Coulon (ed.). Hilaire Van Daele (trad.). París: Les Belles Lettres.

Bajtin, Misail (1989). Teoría y estética de la novela: trabajos de investigación. Helena S. Kriúkova y Vicente Cazcarra (trad.). Madrid: Taurus.

Batany, Jean (1992). «Langage et identités culturelles dans la France médiévale. Du Concile de Tours à la Touraine de Panurge», Approches langagières de la société médiévale. Orleans, Paradigme, pp. 77-94.

${ }^{54}$ Rabelais juega aquí con la tradicional fama de fanfarronería que se atribuía a los militares procedentes de Gascuña, lo que explotará repetidas veces la comedia del siglo XVII. 
Bodel, Jean (i98I). Le Jeu de saint Nicolas. Albert Henry (ed.). Ginebra: Droz.

Bruera, Franca y Meazzi, Barbara, Dir. (2011). Plurilinguisme et Avant-gardes. Frankfurt del Main: Peter Lang.

Brugnolo, Furio (I983). Plurilinguismo e lirica medievale: da Raimbaut de Vaqueiras a Dante. Roma: Buzoni Editore.

Chevaldin, L.-Émile (1903). Les jargons de la Farce de Pathelin, pour la première fois reconstitués, traduits et commentés, avec le bienveillant concours de philologues français et de professeurs d'Universités françaises et étrangères. París: Albert Fontemoing.

Cohen, Gustave (1956). «Rabelais et le théâtre», Études d'Histoire du théâtre en France au Moyen Âge et à la Renaissance. París: Gallimard, pp. 271-326

Colvin, Stephen (1999). Dialect in Aristophanes and the politics of language in ancient Greek literature. Oxford: Clarendon Press.

Cortelazzo, Manlio (I980). «Esperienze ed esperimenti plurilinguistici», Storia della cultura veneta. 3. Dal primo quattrocento al Concilio di Trento. II. Girolamo Arnaldi y Manlio Pastore Stocchi (dirs.). Vicenza: Neri Pozza Editore, pp. 183-213.

Coste, Claude (200I). «Le français macaronique dans le théâtre de la Belle Époque», Altérations, créations dans la langue: les langages dépravés. Anne Tomiche (ed.). ClermontFerrand: Presses Universitaires Blaise Pascal, pp. 271-283.

Coulter, Cornelia C. (1934): «The speech of foreigners in Greek and Latin comedy», Philological Quaterly 13: 133-139.

Dante Alighieri ( I994). La Commedia. Giorgio Petrocchi (ed.). 4 vols. Florencia: Casa Editrice Le Lettere.

Defaux, GÉRARD (I997). Rabelais agonistes: du rieur au prophète: études sur "Pantagruel», «Gargantua», «Le Quart Livre». Ginebra: Droz.

Dull, Olga Anna (I996-I997). «"Escumer le latin”: statut et fonctions de la barbarolexie dans le théâtre comique du XVe siècle; enjeux théoriques», Le Moyen Français 39-41: 205-224.

FORSTER, LEONARD (2009). The poet's tongues: multilinguism in literature. Reimpr. Cambridge: Cambridge University Press. ( $1^{\text {a }}$ ed. 1970).

Garapon, Robert (1957). La fantaisie verbale et le comique dans le théâtre français du Moyen Âge à la fin du XVII siècle. París: Armad Colin.

GaraVini, Fausta (I978). «Poliglottìa ed esperimenti linguistici nella letteratura francese fino a Rabelais», Saggi e ricerche di letterature francese 17: 9-73.

Gauvin, Lise (2004). La fabrique de la langue: de François Rabelais à Réjean Ducharme. París: Le Seuil.

Gelio, Aulo (1978). The Attic Nights. John C. Rolfe (trad.). Cambridge, Mass.; Londres: William Heinemann.

Heller-Roazen, Daniel (2003). «Des altérités de la langue. Plurilinguismes poétiques au Moyen Âge», Littérature 130: 75-96.

Horacio (2002). Epístolas. Arte poética. Fernando Navarro Antolín (ed. y trad.). Madrid: csic.

Huchon, Mireille (1995). «Le plurilinguisme au XVI ${ }^{\mathrm{ème}}$ siècle: jeux et enjeux», Actes du colloque Babel en Poitou: Agrippa d'Aubigné et le plurilinguisme: journées d'études des 29-30 mai 1992.

Poitiers, Musée Sainte-Croix. Jean Brunel (ed.) y Marie-Madeleine Fragonard (pres.). Albineana - Cahiers d'Aubigné 6 (1995) (Niort: Association des Amis d'Agrippa d'Aubigné); Diffusion: París: Honoré Champion, pp. 15-27.

JeAy, Madeleine (2008). «La rencontre des langues dans le récit médiéval», Topographie de la rencontre dans le roman européen. Jean-Pierre Dubost (ed.). Clermont-Ferrand, Presses Universitaires Blaise-Pascal, pp. 19-39.

JOUBERT, LAURENT (I586). Erreurs populaires av faict de la medecine et regime de santé. Aviñón: Pierre Roux. 
Khordoc, Catherine (i999). «Babel: figure de créolisation dans Tambour-Babel d'Ernest Pépin», Les langues du roman: du plurilinguisme comme stratégie textuelle. Lise Gauvin (dir.). Montreal: Les Presses de l'Université de Montréal, pp. 129-145.

KöTLER, CATHERINe Élianne (I995). «Le plurilinguisme, un élément de l'écriture pamphlétaire d'Agrippa d'Aubigné», Actes du colloque Babel en Poitou: Agrippa d'Aubigné et le plurilinguisme: journées d'études des 29-30 mai 1992. Poitiers, Musée Sainte-Croix. Jean Brunel (ed.) y Marie-Madeleine Fragonard (pres.). Albineana - Cahiers d'Aubigné 6 (1995) (Niort: Association des Amis d'Agrippa d'Aubigné); Diffusion: París: Honoré Champion, pp. 307-330.

Kramer, Samuel Noah (i968). «The "Babel of Tongues": A Sumerian version», Journal of the American Oriental Society 88: 108-111.

LANGlois, Charles-Victor (I 893). «Les Anglais du moyen âge d'après les sources françaises», Revue Historique 18.52: 298-315.

LAZZERINI, LuCIA (I982). «Aux origines du macaronique», Revue des Langues Romanes 86.1: 11-33.

Lejeune, Rita (I96I). «Pour quel public La Farce de Maistre Pierre Pathelin a-t-elle été rédigée?», Romania 82.4: 482-521

Lewicka, Halina (I96I). «L'emploi stylistique des dialectes dans le théâtre comique français au $\mathrm{XV}^{\mathrm{e}}$ et au début du XVI $\mathrm{I}^{\mathrm{e}}$ siècle», Kwartalnik Neofilologiczny 8.2: 161-169.

Luciano (1988). Obras. II. José Luis Navarro González (trad. y notas). Madrid: Gredos.

LÜDI, GEORGES (I995). «Éléments pour une histoire du plurilinguisme: polyglossie et pratiques plurilingues chez les Romains», Estudis de lingüística i filologia oferts a Antoni M. Badia $i$ Margarit. Barcelona: Departament de Filologia Catalana, Universitat de Barcelona; Abadia de Montserrat, I, pp. 553-564.

MacPhaIL, ERIC (2008). «The elegance of the ecolier limousin: the european context of Rabelais' linguistic parody», MLN 123.4: 873-894.

Maistre Pierre Pathelin, Farce du XV siècle (1970). 2ed. rev. por Richard T. Holbrook. París: Honoré Champion.

Martineau, Anne (20I I). «L'étrange charabia de Renart dans Renart jongleur (Branche I du Roman de Renart; env. 1190-1195)», L'étrangeté des langues. Yves Clavaron, Jérôme Dutel y Clément Lévy (eds.). Saint-Étienne: Publications de l'Université de Saint-Étienne, pp. 69-80.

Matzke, John E. (1905): «Some examples of French as spoken by Englishmen in old Literature», Modern Philology 3.1: 47-60.

Menéndez Pidal, Ramón (I99I). Poesía juglaresca y juglares: orígenes de las literaturas románicas. $9^{a}$ ed. Rafael Lapesa (pról.). Madrid: Austral.

Molle, Jose Vincenzo (2002). «"La poudre d'oribus”. Mistilinguismo e creazione verbale nel Miracle de Théophile, nelle farse di Maître Pathelin et di Maistre Mimin estudiant, e nelle opera di Rabelais», Eteroglossia e plurilinguismo letterario. II. Plurilinguismo e letteratura. Atti des XXVIII Convegno interuniversitario di Bressanone (6-9 Iuglio 2000). Furio Brugnolo y Vincenzo Orioles (eds.). Roma: il Calamo, pp. 61-101

Oniga, Renato (2007). «Il plurilinguismo nella letteratura latina: problemi e prospettive», Plurilinguismo letterario. Renato Oniga y Sergio Vatteroni (eds). Soveria Mannelli: Rubbettino, Centro Internazionale sul Plurilinguismo, Università degli Studi di Udine, pp. 9-11.

Plauto (2003). Comédies. V. Mostellaria. Persa, Pœnulus. Alfred Ernout (ed. y trad.). $4^{\mathrm{a}}$ reimpr. París: Les Belles Lettres.

Plinio el Viejo (I980). Natural History. VII. W.H.S. Jones (trad.). Cambridge, Mass.: Harvard University Press; Londres: William Heinemann.

Plinio el Viejo (2003). Historia natural. Libros VII-XI. E. del Barrio Sanz, I. García Arribas, A. $\mathrm{M}^{\mathrm{a}}$ Moure Casas, L.A. Hernández Miguel y $\mathrm{M}^{\mathrm{a}}$ L. Arribas Hernáez (trad. y notas). Madrid: Gredos. 
Primot, Carole (20I I). «Le macaronique en France à la Renaissance: de l'étrangeté joyeuse au déchirement hors les règles», L'étrangeté des langues. Yves Clavaron, Jérôme Dutel y Clément Lévy (eds.). Saint-Étienne: Publications de l'Université de Saint-Étienne, pp. 83-92.

Rabelais, François (I994). Euvres complètes. Mireille Huchon (ed.), François Moreau (col.). París, Gallimard, «La Pléiade».

RECUEIL DE PIĖCES RARES ET FACÉTIEUSES, ANCIENNES ET MODERNES, EN VERS ET EN PROSE: REMISE EN LUMIÈRE PouR L'ESBATtement des PANTAGRUÉLISTES (i873). III. París: A. Barraud.

ReCUeIL TREPPEREL (LE) (I935-I96I). I. Les sotties. Eugénie Droz (ed.). París: Droz. II. Les farces. Eugénie Droz y Halina Lewicka (eds.). Ginebra: Droz.

RENZI, LORENZO ( I993). «Un aspetto del plurilinguismo medievale: dalla lingua dei re magi a papè satan aleppe», Omaggio a Gianfranco Folena. Padua: Editoriale Programma, I, pp. 61-73.

Revol, ThIerry (I999). «Charabias et magiciens dans le théâtre des XII $-\mathrm{XIII}{ }^{\mathrm{e}}$ siècles», Magie et illusion au Moyen-Âge, Actes du 23 Colloque du CUER MA, Aix-en-Provence, mars 1998, Université de Provence (Centre d'Aix), 1999 («Senefiance», 42), pp. 491-506.

RiQuer, MARTín DE (1975). Los trovadores: historia literaria y textos. 3 vols. Barcelona: Planeta.

Rochette, Bruno (2007). «Grecs, Romains et barbares: contribution à l'étude de la diversité linguistique dans l'Antiquité classique», Plurilinguismo letterario. Renato Oniga y Sergio Vatteroni (eds.). Soveria Mannelli: Rubbettino, Centro Internazionale sul Plurilinguismo, Università degli Studi di Udine, pp. 13-40.

Rutebeuf (I989-I 990). Euvres complètes. Michel Zink (ed.). 2 vols. París: Classiques Garnier.

SCHNAPP, JeFFrey T. (1990): «Between Babel and Pentecost: Imaginary Languages in the Middle Ages», Recherches et Rencontres. 1. Modernité au Moyen-Âge: le défi du passé. Brigitte Cazelles y Charles Méla (eds.). Ginebra: Droz, pp. 175-206.

Schwob, Marcel (I903). «Ne reminiscaris», Revue des Études Rabelaisiennes 1: 71-73.

Souriau, Étienne (1965). «Sur l'esthétique des mots et des langages forgés», Revue d'Esthétique 18.1: $19-48$.

Tabourot, Étienne (i986). Les bigarrures du Seigneur des Accords (Premier livre). Francis Goyet (ed.). 2 vols. Ginebra: Droz. (Facsímil de la ed. de 1588).

Tavani, Giuseppe (2000). «Il plurilinguismo nella lirica dei trovatori», Documenti letterari del plurilinguismo. Vincenzo Orioles (ed.). Roma: Il Calamo, pp. 123-142

Tomiche, ANNe, ED. (2001): Altérations, créations dans la langue: les langages dépravés. Clermont-Ferrand: Presses Universitaires Blaise Pascal.

TORY, GEOFFroy (I998). Champ fleury auquel est contenu l'art et science de la vraye proportion des lettres attiques, qu'on dit autrement lettres antiques, \& vulgairement lettres romaines proportionnees selon le corps et visage humain. París: Bibliothèque de l'Image. (Facsímil de la ed. de 1529).

VTIL Y BREVE INSTITVTION PARA APRENDER LOS PRINCIPIOS Y FUNDAMENTOS DE LA LENGUA HESPAÑOLA (I977). Antonio Roldán (ed.). Madrid, CSIC (Facsímil de la ed. de Lovaina, 1555).

WILLI, ANDREAS (2003). The languages of Aristophanes: aspects of linguistic variation in classical Attic Greek. Oxford University Press.

ZINK, Michel (I995). «Plurilingualism, hermeticism, and love in medieval poetics», Comparative Literature Studies 32.2: 112-130.

Zumthor, Catherine Paul, (I985). «Archaïsme et fiction: les plus anciens documents de langue "romane"», La linguistique fantastique. Sylvain Auroux, Jean-Claude Chevalier, Nicole Jacques-Chaquin y Christiane Marchello-Nizia (dirs.). París: Joseph Clims; Denoël, pp. 285-299

Zumthor, Paul (I960). «Un problème d'esthétique médiévale: l'utilisation poétique du bilinguisme», Le Moyen Âge 6.6: 301-336 y 561-594. 
